\title{
Fe(II) spin crossover complexes of a derivative of 2,6- bis(pyrazol-1-yl)pyridine (1-bpp) functionalized with a carboxylic acid in the 3-pyridyl position
}

\author{
V. García-López, M. Palacios-Corella, M. Clemente-León,* E. Coronado
}

Instituto de Ciencia Molecular, Universidad de Valencia, Catedrático José Beltrán 2, 46980, Spain

\begin{abstract}
The preparation of a new bis(pyrazol-1-yl)pyridine (1-bpp) derivative functionalized with a carboxylic acid in the 3-pyridyl position, bpp3-COOH ligand is reported together with the structure and spin-crossover (SCO) properties of $\left[\mathrm{Fe}^{\mathrm{II}}(\mathrm{bpp} 3-\mathrm{COOH})_{2}\right]\left(\mathrm{ClO}_{4}\right)_{2} \cdot 0.5 \mathrm{EtOH} \cdot 0.5 \mathrm{H}_{2} \mathrm{O}$ (1). Magnetic properties of $\mathbf{1}$ indicate that LS is favored. Desolvation leads to a gradual and incomplete SCO. Solvated and desolvated compounds show LIESST effect.
\end{abstract}

Keywords: Magnetic properties / 2,6-bis-(pyrazol1-yl)pyridine / Coordination chemistry / Spin crossover / Iron(II) / LIESST 


\section{Introduction}

Mononuclear Fe(II) complexes capable of undergoing spin-crossover (SCO) from the diamagnetic low-spin state ( $\mathrm{LS}, \mathrm{S}=0)$ to the paramagnetic high-spin state $(\mathrm{HS}, \mathrm{S}=2$ ) are of current interest because of their potential use for applications such as sensors, memories or as part of spintronic devices [1, 2]. Bis-chelated complexes of the tridentate ligand 2,6-bis(pyrazol-1-yl)pyridine (bpp) constitute one of the most studied families of $\mathrm{Fe}$ (II) SCO complexes, since they usually present abrupt thermal spin transitions at accessible temperatures and Light-Induced Excited Spin State Trapping (LIESST) effect [3]. In addition to this, they can be functionalized in several positions of the bpp framework without perturbing significantly the SCO properties of the complexes [4].

In previous works, we prepared the Fe(II) complex of bpp ligand functionalized with a carboxylic acid at the 4-pyridyl position (2,6-di(pyrazol-1-yl)-pyridine-4-dicarboxylic acid, bppCOOH, see Scheme 1). We showed that the solvent-free $\mathrm{ClO}_{4}{ }^{-}$and $\mathrm{BF}_{4}^{-}$salts of $\left[\mathrm{Fe}^{\mathrm{II}}(\mathrm{bppCOOH})_{2}\right]^{2+}$ exhibit abrupt thermal and light-induced spin transition related to the presence of a hydrogen-bonded linear network of complexes, whereas the incorporation of solvent molecules in the structure of the $\mathrm{CF}_{3} \mathrm{SO}_{3}{ }^{-}, \mathrm{AsF}_{6}^{-}$an $\mathrm{SbF}_{6}^{-}$salts induces reversible solvent-induced SCO [5-6]. The carboxylic acid of these SCO complexes could be used for the preparation of polynuclear metal complexes [7]. Besides, it has been shown recently that $\mathrm{Co}(\mathrm{II})$ complexes of bppCOOH and related ligands may exhibit a Single-molecule Magnet (SMM) behavior [8].

In this work, we have prepared the Fe(II) complex of a new derivative of bpp bearing a carboxylic acid at the 3-pyridyl position (bpp3-COOH, see scheme 1). The aim of this work is to explore the SCO properties induced by the change in position of this functional group, which could offer new possibilities for the preparation of 
organized assemblies of these SCO units by coordination to other metals or deposition on surfaces.
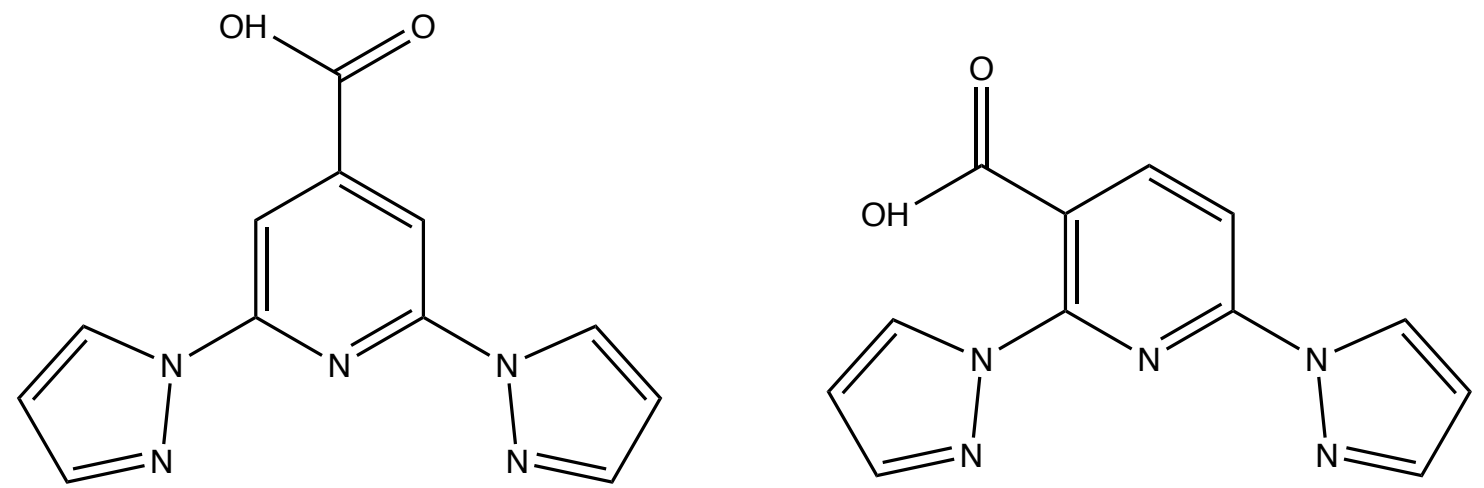

Scheme 1. Molecular structures of bppCOOH (left) and bpp3-COOH (right).

\section{Materials and methods}

\section{Synthesis of bpp3-COOH}

Under an argon atmosphere, $\mathrm{NaH}$ (560 $\mathrm{mg}, 23 \mathrm{mmol})$ was suspended in dimethylformamide (DMF) (15mL). Pyrazole (1.02 g, $15 \mathrm{mmol})$ dissolved in DMF $(10 \mathrm{~mL})$ was added very slowly. The mixture was heated at $100^{\circ} \mathrm{C}$ for one hour and pyridine-3-carboxylic acid (500 $\mathrm{mg}, 2.6 \mathrm{mmol})$ was added. The mixture was heated to $130{ }^{\circ} \mathrm{C}$ for 3 days. The solvent was eliminated under vacuum and water was added. The yellow solution obtained was acidified with $\mathrm{HCl}$ to $\mathrm{pH}$ 2.7. A white precipitate was obtained and filtered. ${ }^{1} \mathrm{H}$ NMR (MeOD, $300 \mathrm{MHz}$ ): $\delta 6.55$ (dd, Pz), 6.57 (dd, Pz) , 7.74 (dd, Pz), 7.81 (dd, Pz), 7.93 (s, Py), 7.96 (s, Py), 8.24 (s, Py), 8.28 (s, Py), 8.5 (dd, Pz) , $8.71(\mathrm{dd}, \mathrm{Pz})$.

CAUTION: The perchlorate salts of metal complexes with organic ligands are potentially explosive. Only small quantities of the compound should be prepared and handled with much care!

\section{Synthesis of $\left[\mathrm{Fe}(\mathrm{bpp} 3-\mathrm{COOH})_{2}\right]\left(\mathrm{ClO}_{4}\right)_{2} \cdot 0.5 \mathrm{EtOH} \cdot 0.5 \mathrm{H}_{2} \mathrm{O}(1)$.}

A solution of $\mathrm{Fe}\left(\mathrm{ClO}_{4}\right)_{2} \cdot \mathrm{xH}_{2} \mathrm{O}(6.4 \mathrm{mg}, 0.025 \mathrm{mmol})$ in ethanol $(1 \mathrm{~mL})$ was added to a solution of bpp3-COOH $(14.3 \mathrm{mg}, 0.050 \mathrm{mmol})$ in ethanol $(2 \mathrm{~mL})$ and 
the mixture was stirred for 15 minutes. An orange solution was formed. Red prismatic crystals of $\mathbf{1}$ suitable for X-ray diffraction were obtained by slow diffusion of diethyl ether into this solution. The composition of crystals of $\mathbf{1}$, checked by microanalysis, shows a $\mathrm{Fe}: \mathrm{Cl}$ ratio close to 1:2. Anal. Calcd for $\left[\mathrm{Fe}(\mathrm{bpp} 3-\mathrm{COOH})_{2}\right]\left(\mathrm{ClO}_{4}\right)_{2} \cdot 4 \mathrm{H}_{2} \mathrm{O}: \mathrm{C}, 34.43 ; \mathrm{H}, 3.13 ; \mathrm{N}, 16.73 \%$. Found: $\mathrm{C}$, $34.26 ; \mathrm{H}, 2.96 ; \mathrm{N}, 16.49 \%$.

\section{Synthesis of $\left[\mathrm{Fe}(\mathrm{bpp} 3-\mathrm{COOMe})_{2}\right]\left(\mathrm{ClO}_{4}\right)_{2}(2)$.}

A solution of $\mathrm{Fe}\left(\mathrm{ClO}_{4}\right)_{2} \cdot \mathrm{xH}_{2} \mathrm{O}(6.4 \mathrm{mg}, 0.025 \mathrm{mmol})$ in methanol $(1 \mathrm{~mL})$ was added to a solution of bpp3-COOH (14.3 $\mathrm{mg}, 0.050 \mathrm{mmol})$ in methanol (2 $\mathrm{mL})$ and the mixture was stirred for 15 minutes. An orange solution was formed. Red prismatic crystals of $\mathbf{2}$ suitable for X-ray diffraction were obtained by slow diffusion of diethyl ether into this solution. The composition of crystals of $\mathbf{2}$, checked by microanalysis, shows a $\mathrm{Fe}: \mathrm{Cl}$ ratio close to $1: 2$.

\section{Crystallography}

Single crystals of $\mathbf{1}$ and $\mathbf{2}$ were mounted on glass fibers using a viscous hydrocarbon oil to coat the crystal and then transferred directly to the cold nitrogen stream for data collection. Reflection data were collected at $120 \mathrm{~K}$ on a Supernova diffractometer equipped with a graphite-monochromated Enhance (Mo) X-ray Source $(\lambda=0.7107 \AA)$. The CrysAlisPro program, Oxford Diffraction Ltd., was used for unit cell determinations and data reduction. Empirical absorption correction was performed using spherical harmonics, implemented in the SCALE3 ABSPACK scaling algorithm. Crystal structure was solved by direct methods with the SIR97 program [9], and refined with the SHELXL-2013 program [10], using Olex2 [11]. All non-hydrogen atoms were refined anisotropically except as noted and hydrogen atoms were placed in 
calculated positions and refined isotropically with a riding model. Crystallographic data are summarized in Table 1. CCDC-1910175-6 contains the supplementary crystallographic data for this paper. These data can be obtained free of charge from The Cambridge Crystallographic Data Centre via www.ccdc.cam.ac.uk/data_request/cif. A $0.5 \mathrm{~mm}$ glass capillar was filled with a polycrystalline sample of $\mathbf{1}$ and mounted and aligned on a Empyrean PANalytical powder diffractometer, using $\mathrm{CuK} \alpha$ radiation $(\lambda=1.54177 \AA)$. A total of 2 scans were collected at room temperature in the $2 \theta$ range $5-40^{\circ}$.

\section{Physical Measurements}

The $\mathrm{Fe} / \mathrm{Cl}$ ratios were measured with a Philips ESEM X230 scanning electron microscope equipped with an EDAX DX-4 microsonde. ${ }^{1} \mathrm{H}$ NMR spectra were acquired on a Bruker AVANCE DRX 300 spectrometer. Elemental analyses $(\mathrm{C}, \mathrm{H}$, and $\mathrm{N})$ were performed with a CE Instruments EA 1110 CHNS Elemental analyzer. Thermogravimetric analysis was carried out using a Mettler Toledo TGA/SDTA 851 apparatus. A Q-TOF Premier mass spectrometer with an orthogonal Z-spray electrospray source (Waters, Manchester, U.K.) was used for Electrospray ionization mass spectrometry (ESI-MS). The temperature of the source block was set to $100{ }^{\circ} \mathrm{C}$ and the desolvation temperature to $120^{\circ} \mathrm{C}$. A capillary voltage of $3.3 \mathrm{kV}$ was used in the positive scan mode, and the cone voltage was set to $5 \mathrm{~V}$ to control the extent of fragmentation of the identified species. TOF mass spectra were acquired in the $\mathrm{W}$-mode operating at a resolution of ca. 15000 (fwhm). Mass calibration was performed using a solution of sodium iodide in isopropanol/water (50:50) from $\mathrm{m} / \mathrm{z} 50$ to 3000 . Acetonitrile sample solutions were infused via syringe pump directly connected to the ESI source at a flow rate of $10 \mu \mathrm{L} / \mathrm{min}$. Magnetic measurements were performed with Quantum Design MPMS-XL-5 SQUID magnetometer on powdered polycrystalline 
samples. Photomagnetic measurements were performed irradiating with a Diode Pumped Solid State Laser DPSS-532-20 from Chylas and a coupled via an optical fiber to the cavity of the SQUID magnetometer. The optical power at the sample surface was adjusted to $2 \mathrm{~mW} \cdot \mathrm{cm}^{-2}$, and it was verified that it resulted in no significant change in magnetic response due to heating of the sample. The photomagnetic samples consisted of a thin layer of compound whose weight was corrected by comparison of a thermal spin crossover curve with that of a more accurately weighted sample of the same compound.

\section{Results and discussion}

\section{Synthesis}

The bpp3-COOH ligand was obtained for the first time in this work following a similar synthetic procedure to that used with bppCOOH by reacting dichloronicotinic acid and the pyrazolyl radical generated in situ with sodium hydride [12]. The $\left[\mathrm{Fe}(\mathrm{bpp} 3-\mathrm{COOH})_{2}\right]^{2+}$ complex was prepared by slow diffusion of diethyl ether into solutions of $\mathrm{Fe}\left(\mathrm{ClO}_{4}\right)_{2} \cdot \mathrm{xH}_{2} \mathrm{O}$ and bpp3-COOH in a 1:2 molar ratio in acetone, acetonitrile, ethanol and methanol. In ethanol, only one type of crystals of the compound $\left[\mathrm{Fe}(\mathrm{bpp} 3-\mathrm{COOH})_{2}\right]\left(\mathrm{ClO}_{4}\right)_{2} \cdot 0.5 \mathrm{EtOH} \cdot 0.5 \mathrm{H}_{2} \mathrm{O}$ (1) were obtained. Powder X-ray diffraction (PXRD) pattern (See ESI: Figure S1) confirms the purity of the compound and the structure obtained from single crystal X-ray diffraction (see below). Furthermore, it confirms that $\mathbf{1}$ retains its structural integrity on exposure to air, despite the tendency of $\mathbf{1}$ to absorb water molecules. Thus, thermogravimetric analysis of $\mathbf{1}$ shows a weight decrease of 2 $\%$ in the 300-370 K range (See ESI: Figure S2). This weight loss is not in agreement with the EtOH and $\mathrm{H}_{2} \mathrm{O}$ molecules found in the structure (expected weight loss of $4 \%$ ) and is more consistent with the loss of one water molecule. 
This suggests replacement of EtOH by $\mathrm{H}_{2} \mathrm{O}$ after extracting the crystals from the mother liquor. On the other hand, elemental analysis of an older sample agrees with the formula $\left[\mathrm{Fe}(\mathrm{bpp} 3-\mathrm{COOH})_{2}\right]\left(\mathrm{ClO}_{4}\right)_{2} \cdot 4 \mathrm{H}_{2} \mathrm{O}$ (see experimental section), indicating a larger absorption of water molecules with time.

In contrast to this, single crystal structure of the compound obtained in methanol showed that, instead of the expected $\left[\mathrm{Fe}(\mathrm{bpp} 3-\mathrm{COOH})_{2}\right]^{2+}$ complex, the complex of methyl ester (bpp3-COOMe) was obtained in the compound of formula $\left[\mathrm{Fe}(\mathrm{bpp} 3-\mathrm{COOMe})_{2}\right]\left(\mathrm{ClO}_{4}\right)_{2}$ (2) (See ESI: Figure S3 and table S1). This was confirmed by ESI-MS (See ESI: Figure S4 and associated text). This esterification reaction of the carboxylic acid with the methanol solvent molecules is favored when the ligand is coordinated to the $\mathrm{Fe}(\mathrm{II})$ ion since similar conditions in absence of $\mathrm{Fe}(\mathrm{II})$ salt did not lead to the formation of the ester. Further characterization by single crystal X-ray diffraction and ESI-MS of the crystals obtained in different positions of the diffusion tube indicated that the slow reaction of bpp3-COOH with $\mathrm{MeOH}$ in the complex at different methanol/diethyl ether concentrations gave rise to a mixture of compounds containing the homoleptic $\left[\mathrm{Fe}(\mathrm{bpp} 3-\mathrm{COOH})_{2}\right]^{2+}$ and $\left[\mathrm{Fe}(\mathrm{bpp} 3-\mathrm{COOMe})_{2}\right]^{2+}$ and the heteroleptic $[\mathrm{Fe}(\mathrm{bpp} 3-\mathrm{COOMe})(\mathrm{bpp} 3-\mathrm{COOH})]^{2+}$ complexes, which are difficult to separate (See ESI: Figure $\mathbf{S 4}$ and associated text). The optimization of these syntheses to obtain the pure homoleptic and heteroleptic complexes of these ligands in methanol is in progress. Due to the problems to obtain the pure complex in other solvents we have focused our studies in $\mathbf{1 .}$

Structure of $\left[\mathrm{Fe}(\mathrm{bpp} 3-\mathrm{COOH})_{2}\right]\left(\mathrm{ClO}_{4}\right)_{2} \cdot 0.5 \mathrm{EtOH} \cdot 0.5 \mathrm{H}_{2} \mathrm{O}(1)$

This compound crystallizes in the tetragonal crystal system with the noncentrosymmetric achiral $I-42 \mathrm{~d}$ space group. The asymmetric unit is composed by 
half $\left[\mathrm{Fe}(\mathrm{bpp} 3-\mathrm{COOH})_{2}\right]^{2+}$ cation, two half perchlorate anions and one ethanol and water disordered solvent molecules. The central iron(II) ion of the complex presents a multiplicity of 0.5 due to the presence of 2-fold and 4-fold rotoinversion axes. It is coordinated by six nitrogen atoms from two tridentate bpp3-COOH ligands with a distorted octahedral coordination geometry (see Fig. 1). The short Fe-N bond lengths at $120 \mathrm{~K}(1.865(10)-1.992(17) \AA)$ clearly indicate that the complex is in the LS state in agreement with magnetic measurements. The coordination geometry is close to the ideal $D_{2 \mathrm{~d}}$ symmetry associated to a $\left[\mathrm{Fe}(1-\mathrm{bpp})_{2}\right]^{2+}$. Thus, (trans-N(pyridyl)-Fe-N(pyridyl) angle $(\phi)$ of $180^{\circ}$ and dihedral angle between the least squares planes of the two ligands $(\theta)$ close to $88.7^{\circ}$ are obtained. These values are consistent with those of other LS bpp complexes exhibiting SCO [3]. The carboxylic acid group presents a disorder, which has been solved with two possible configurations with 0.5 occupancies. The crystal packing of the complexes is shown in Fig. 2. [Fe(bpp3$\left.\mathrm{COOH})_{2}\right]^{2+}$ complexes are surrounded by $\mathrm{ClO}_{4}^{-}$anions and disordered solvent molecules forming chains, which run along the $c$ axis. There are two types of intermolecular interactions between $\left[\mathrm{Fe}(\mathrm{bpp} 3-\mathrm{COOH})_{2}\right]^{2+}$ complexes: $\mathrm{CH} \cdots \mathrm{O}$ contacts between pyrazole groups and $\mathrm{O}$ atoms from carboxylic acid groups and $\mathrm{O} \cdots \mathrm{O}$ contacts between $\mathrm{O}$ atoms from carboxylic acid groups of neighboring molecules. In contrast to $\left[\mathrm{Fe}(\mathrm{bppCOOH})_{2}\right]^{2+}$ salts of $\mathrm{ClO}_{4}^{-}[5], \mathrm{BF}_{4}^{-}$or $\mathrm{CF}_{3} \mathrm{SO}_{3}^{-}$ $[6]$, there are not hydrogen bond interactions among $\left[\mathrm{Fe}(\mathrm{bpp} 3-\mathrm{COOH})_{2}\right]^{2+}$ complexes in this compound. The two carboxylic acid groups of [Fe(bpp3$\left.\mathrm{COOH})_{2}\right]^{2+}$ are involved in hydrogen-bonds with two $\mathrm{ClO}_{4}^{-}$and two ethanol molecules (See ESI: Figure S5). 


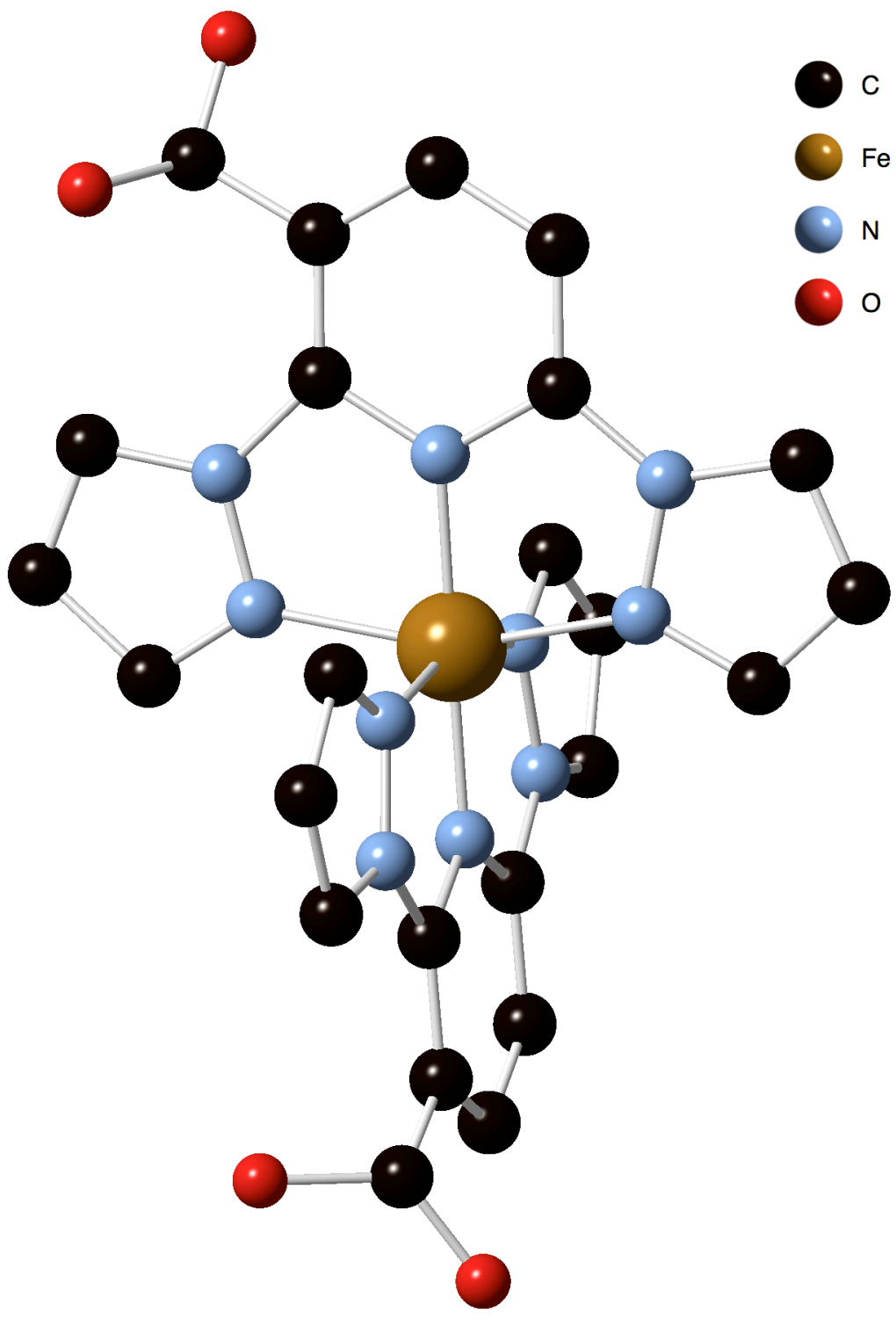

Fig. 1. Structural view of $\left[\mathrm{Fe}(\mathrm{bpp} 3-\mathrm{COOH})_{2}\right]^{2+}$ complex in 1; hydrogen atoms have been omitted for clarity; only one of the two possible configurations of disordered carboxylic acid groups is shown for clarity. 


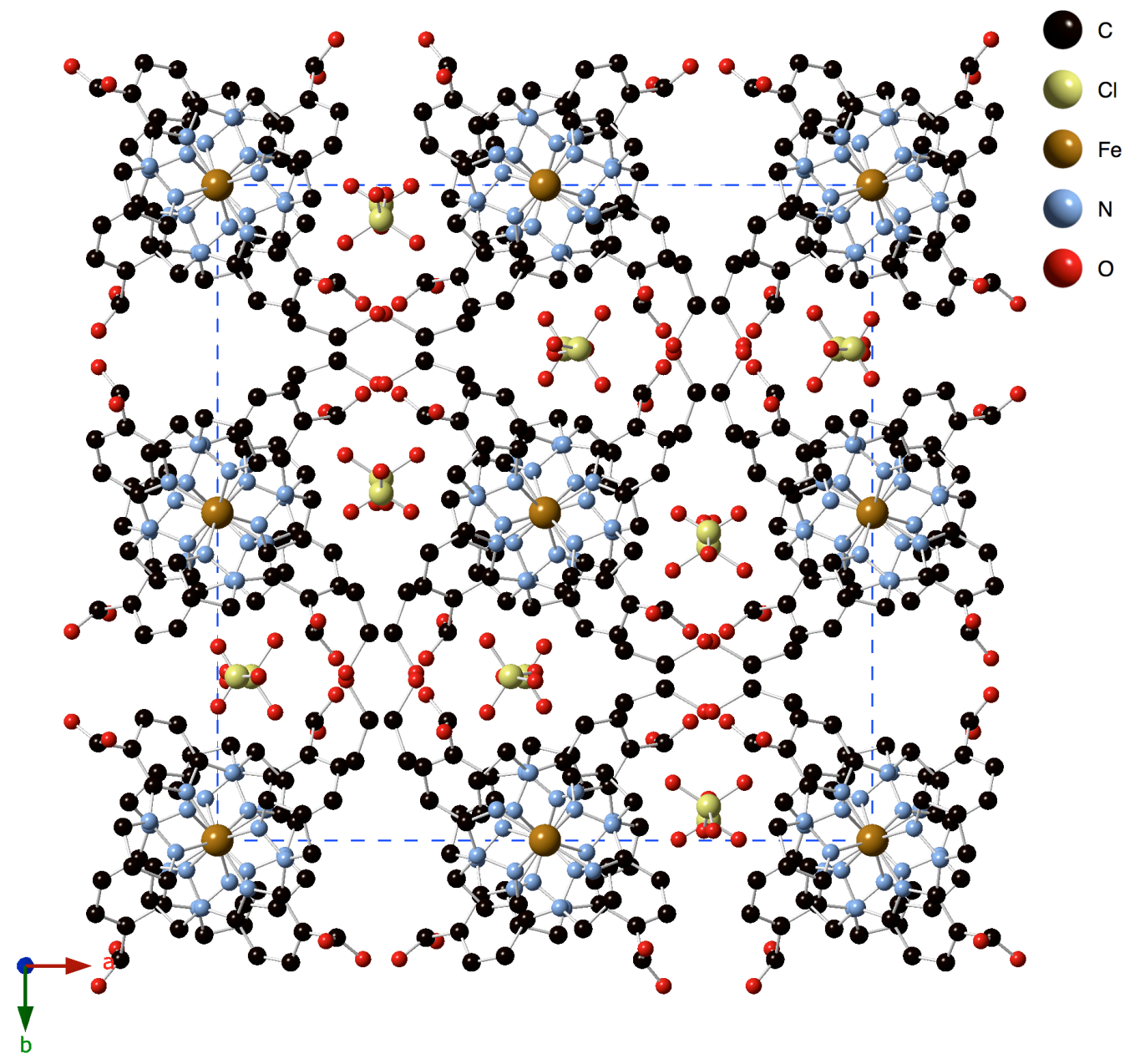

Fig. 2. Projection on the $a b$ plane of the structure of $\mathbf{1}$; hydrogen atoms have been omitted for clarity; only one of the two possible configurations of disordered carboxylic acid groups is shown for clarity.

Table 1. Crystallographic data for $\mathbf{1 .}$

\begin{tabular}{ll}
\hline Empirical formula & $\mathrm{C}_{50} \mathrm{H}_{32} \mathrm{~N}_{20} \mathrm{O}_{26} \mathrm{Cl}_{4} \mathrm{Fe}_{2}$ \\
Formula weight & 1582.45 \\
Temperature/K & 120.15 \\
Crystal system & tetragonal \\
Space group & $\mathrm{I}-42 \mathrm{~d}$ \\
a/A & $21.359(3)$ \\
b/A & $21.359(3)$ \\
c/ & $15.1623(19)$
\end{tabular}


$\alpha /^{\circ}$

$\beta /^{\circ}$

$\gamma^{\circ}$

Volume $/ \AA^{3}$

Z

$\varrho_{\text {calc }} \mathrm{g} / \mathrm{cm}^{3}$

$\mu / \mathrm{mm}^{-1}$

Crystal size $/ \mathrm{mm}^{3}$

Radiation

$2 \Theta$ range for data collection/ ${ }^{\circ}$

Reflections collected

Independent reflections

Data/restraints/parameters

Goodness-of-fit on $\mathrm{F}^{2}$

Final $\mathrm{R}$ indexes [I>=2 $\sigma(\mathrm{I})]$

Final R indexes [all data]

Flack parameter

6917.4(19)

0.666

$0.28 \times 0.03 \times 0.02$

$\operatorname{MoK} \alpha(\lambda=0.71073)$

6.59 to 53.118

48871

$3571\left[R_{\text {int }}=0.2168, R_{\text {sigma }}=0.1044\right]$

$3571 / 37 / 225$

1.031

$\mathrm{R}_{1}=0.1299, \mathrm{wR}_{2}=0.3230$

$\mathrm{R}_{1}=0.2449, \mathrm{wR}_{2}=0.3960$

$-0.06(5)$

\section{Magnetic properties}

The temperature dependence of the product of the magnetic susceptibility times temperature $\left(\chi_{M} T\right)$ of 1 shows a value close to 0 from 300 to $2 \mathrm{~K}$ in the cooling and heating modes (see Fig. 3). This indicates a diamagnetic LS state of the $\mathrm{Fe}(\mathrm{II})$ complexes in agreement with $\mathrm{Fe}-\mathrm{N}$ bond lengths from the structure at $120 \mathrm{~K}$ (see above). A similar behavior has been observed in other $\mathrm{Fe}(\mathrm{II})$ complexes of bpp bearing carboxy substitutents, which often exhibit SCO well above room temperature in the solid state $[5,6,13]$. At temperatures above 330 $\mathrm{K}$, there is an abrupt increase to reach a value of $2.0 \mathrm{~cm}^{3} \cdot \mathrm{K}^{\prime} \cdot \mathrm{mol}^{-1}$ at $400 \mathrm{~K}$ 
corresponding to around $60 \%$ of molecules in the HS state taking a value of 3.5 $\mathrm{cm}^{3} \mathrm{~K} \mathrm{~mol}{ }^{-1}$ for the pure HS state. This partial SCO is irreversible as $\chi_{M} T$ of $\left[\mathrm{Fe}(\mathrm{bpp} 3-\mathrm{COOH})_{2}\right]\left(\mathrm{ClO}_{4}\right)_{2} \cdot 0.5 \mathrm{EtOH} \cdot 0.5 \mathrm{H}_{2} \mathrm{O}$ decreases gradually after heating to $400 \mathrm{~K}$ to reach a plateau of $0.6 \mathrm{~cm}^{3} \cdot \mathrm{K} \cdot \mathrm{mol}^{-1}$ at temperatures below $100 \mathrm{~K}$. The irreversibility of this behavior indicates that it is related to the loss of the solvent molecules observed in the structure at $120 \mathrm{~K}\left(\mathrm{EtOH}\right.$ and $\left.\mathrm{H}_{2} \mathrm{O}\right)$. Indeed, PXRD of the desolvated sample shows an irreversible loss of crystallinity. Therefore, the solvated compound is mostly LS in all the range of temperatures, while the desolvated one shows a gradual and partial SCO from 400 to $100 \mathrm{~K}$ related to an irreversible change of structure. 


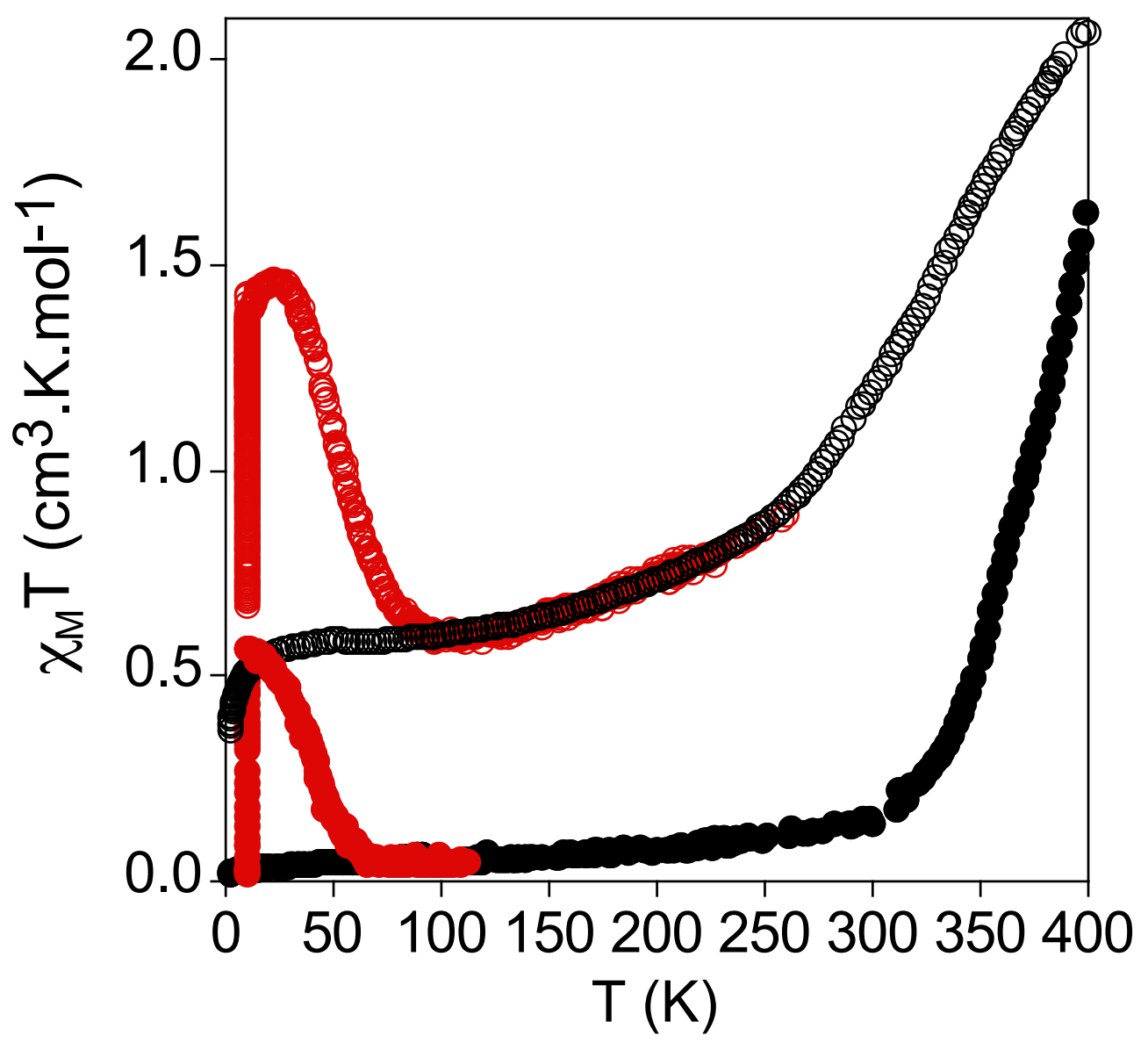

Fig. 3. Temperature dependence of the product of the molar magnetic susceptibility times temperature $\left(\chi_{M} T\right)$ at $0.1 \mathrm{~T}$ for desolvated (full circles) and solvated (empty circles) 1 before (black) and after (red) irradiation.

\section{Photomagnetic properties}

The photomagnetic properties of the solvated (freshly filtered crystals) and desolvated 1 (heated previously in the squid at $400 \mathrm{~K}$ ) were measured after irradiation at $10 \mathrm{~K}$ at $532 \mathrm{~nm}$. A clear increase of the magnetic signal is observed in the two samples. After the irradiation was switched off, the temperature was increased at $0.3 \mathrm{~K} \cdot \mathrm{min}^{-1}$ and the magnetic susceptibility recorded (see Fig. 3). The 
maximum $\chi_{\mathrm{M}} \mathrm{T}$ value of solvated 1 after irradiation is $0.6 \mathrm{~cm}^{3} \cdot \mathrm{K} \cdot \mathrm{mol}^{-1}$, which indicates that about $15 \%$ of $\mathrm{Fe}(\mathrm{II})$ has been photo-converted. The LIESST temperature (T(LIESST)), defined as the minimum of the derivate of $\chi_{\mathrm{M}} \mathrm{T}$ with temperature, is $40 \mathrm{~K}$. The photoconversion and $T(\mathrm{LIESST})$ increase in desolvated 1. Thus, an increase of ca. $1 \mathrm{~cm}^{3} \mathrm{~K} \mathrm{~mol}^{-1}$ is observed for the maximum value of $\chi_{\mathrm{M}} \mathrm{T}$ of desolvated 1 after irradiation. This corresponds to about $30 \%$ of LS to HS photoconversion. On the other hand, T(LIESST) of desolvated $\mathbf{1}$ is $50 \mathrm{~K}$. Therefore, the decrease of the thermal SCO of the desolvated sample gives rise to an increase of $T$ (LIESST) as expected by the "inverse energy gap law" described by Hauser that predicts that the higher spin transition temperatures leads to faster relaxation of the photoinduced HS metastable state [14].

\section{Conclusions}

In this work we report the preparation of the new bpp ligand derivative, bpp3$\mathrm{COOH}$, and the structure and $\mathrm{SCO}$ properties of the $\mathrm{ClO}_{4}^{-}$salt of its $\mathrm{Fe}(\mathrm{II})$ complex in compound 1. A comparison with the Fe(II) complexes of the carboxylic acid derivative bppCOOH, with carboxylic acid in the 4-pyridyl position instead of the 3-pyridyl one of bpp3-COOH leads to the following conclusions: i) LS state is favored in the solvated and desolvated bulk [Fe(bpp3$\left.\mathrm{COOH})_{2}\right]\left(\mathrm{ClO}_{4}\right)_{2}$ compound as observed in the $\left[\mathrm{Fe}(\mathrm{bppCOOH})_{2}\right]^{2+}$ salts; (ii) the change of position of the carboxylic acid groups induces hydrogen-bond with solvent molecules and counteranions but not between complexes in contrast to the $\mathrm{ClO}_{4}^{-}, \mathrm{BF}_{4}^{-}$and $\mathrm{CF}_{3} \mathrm{SO}_{3}^{-}$salts of $\left[\mathrm{Fe}(\mathrm{bppCOOH})_{2}\right]^{2+}$; (iii) the bulky carboxylic acid group in 3-pyridyl position prevents the presence of other strong intermolecular interactions among the complexes such as $\mathrm{CH} \cdots \pi$ or $\pi \cdots \pi$ stacking interactions found in the "terpyridine embrace" crystal packing typical of bpp 
$\mathrm{Fe}(\mathrm{II})$ complexes [3]. As a result of all this, a gradual and incomplete SCO is observed. The compound presents LIESST effect.

This ligand, as bppCOOH, could be a convenient precursor to new bpp derivatives with other functionalities in addition to the SCO properties. Indeed, the reactivity of the $\mathrm{Fe}(\mathrm{II})$ complex is enhanced for the esterification reaction. On the other hand, a possible advantage of the change of position of the substituent group of bpp is that this could favor the formation of $\mathrm{Fe}$ (II) complexes crystallizing in non-centrosymmetric structures as $\mathbf{1}$, which would confer new properties such as ferroelectrics. This could be favored by functionalizing the same position with bulkier subtituents. Finally, bpp3-COOH is a suitable ligand for the preparation of organized assemblies of SCO or SMM complexes using $\mathrm{Fe}(\mathrm{II})$ or $\mathrm{Co}(\mathrm{II})$, respectively, thanks to the incorporation of the carboxylic acid group. The preparation of polynuclear complexes or extended networks based on 1 and the study of the SMM properties and deposition of the cobalt(II) complex of bpp3-COOH are in progress and will be presented in future works.

\section{Acknowledgements}

Financial support from the EU (ERC Advanced Grant MOL-2D 788222), the Spanish MINECO (MAT-2017-89993-R), the Generalitat Valenciana (Prometeo) is gratefully acknowledged. We thank J. M. Martínez-Agudo and G. Agustí from the Universidad de Valencia for the magnetic measurements. Cristian VicentBarrera from Universitat Jaume $\mathrm{I}$ is gratefully acknowledged for ESI-MS measurements. 


\section{References}

[1] a) P. Gütlich, H.A. Goodwin (eds), Spin Crossover in Transition Metal Compounds, Topics in Current Chemistry, Springer Verlag, Berlin-Heidelberg-New York, 2004, vols. 233-235;

(b) M. A. Halcrow (ed), Spin-crossover materials - properties and applications, John Wiley \& Sons, Chichester, UK, 2013.

[2] (a) K. S. Kumar, M. Ruben, Coord. Chem. Rev. 346 (2017) 176;

(b) G. Molnár, S. Rat, L. Salmon, W. Nicolazzi, A. Bousseksou, Adv. Mater. 30 (2018) 17003862.

[3] (a) M. A. Halcrow, Coord. Chem. Rev. 249 (2005) 2880;

(b) M. A. Halcrow, Coord. Chem. Rev. 253 (2009) 2493;

(c) J. Olguín, S. Brooker, Coord. Chem. Rev. 255 (2011) 203;

(d) M. A. Halcrow, New J. Chem. 38 (2014) 1868;

(e) L. J. Kershaw Cook, R. Mohammed, G. Sherborne, T. D. Roberts, S. Alvarez, M. A. Halcrow, Coord. Chem. Rev. 289-290 (2015) 2.

[4] (a) M. Nihei, L. Han, H. Oshio, J. Am. Chem. Soc. 129 (2007) 5312;

(b) M. Nihei, N. Takahashi, H. Nishikawa, H. Oshio, Dalton Trans. 40 (2011) 2154;

(c) R. González-Prieto, B. Fleury, F. Schramm, G. Zoppellaro, R. Chandrasekar, O.

Fuhr, S. Lebedkin, M. Kappes, M. Ruben, Dalton Trans. 40 (2011) 7564:

(d) K. Takahashi, Y. Hasegawa, R. Sakamoto, M. Nishikawa, S. Kume, E. Nishibori, H. Nishihara, Inorg. Chem. 51 (2012) 5188;

(e) A. Santoro, L. J. Kershaw Cook, R. Kulmaczewski, S. A. Barrett, O. Cespedes, M. A. Halcrow, Inorg. Chem. 54 (2015) 682;

(f) A. Abhervé, M. Palacios-Corella, J. M. Clemente-Juan, R. Marx, P. Neugebauer, J. van Slageren, M. Clemente-León, E. Coronado, J. Mater. Chem. C 3 (2015) 7936; 
(g) R. Kulmaczewski, E. Trzop, L. J. Kershaw Cook, E. Collet, G. Chastanet, M. A. Halcrow, Chem. Commun. 53 (2017) 13268;

(h) B. Schaefer, T. Bauer, I. Faus, J. A. Wolny, F. Dahms, O. Fuhr, S. Lebedkin, H. C. Wille, K. Schlage, K. Chevalier, F. Rupp, R. Diller, V. Schünemann, M. Kappes, M. Ruben, Dalton Trans. 46 (2017) 2289;

(i) I. Galadzhun, R. Kulmaczewski, O. Cespedes, M. Yamada, N. Yoshinari, T. Konno, M. A. Halcrow, Inorg. Chem. 57 (2018) 13761;

(j) M. Attwood, H. Akutsu, L. Martin, D. Cruickshank, S. S. Turner, Dalton Trans. 48 (2019) 90;

(k) K. Senthil Kumar, E. Moreno-Pineda, B. Heinrich, S. Vela, C. Bailly, M. Ruben, Dalton Trans. 48 (2019) 3825.

[5] A. Abhervé, M. Clemente-León, E. Coronado, C. J. Gómez-Garcia, M. LópezJordà, Dalton Trans. 43 (2014) 9406.

[6] V. García-López, M. Palacios-Corella, A. Abhervé, I. Pellicer-Carreño, C.

Desplanches, M. Clemente-León, E. Coronado, Dalton Trans. 47 (2018) 16958.

[7] A. Abhervé, M. J. Recio-Carretero, M. López-Jordà, J. M. Clemente-Juan, J. Canet-Ferrer, A. Cantarero, M. Clemente-León, E. Coronado, Inorg. Chem. 55 (2016) 9361 .

[8] (a) V. García-López, F.J. Orts-Mula, M. Palacios-Corella, J.M. Clemente-Juan, M. Clemente-León, E. Coronado, Polyhedron 150 (2018) 54;

(b) L. Rigamonti, N. Bridonneau, G. Poneti, L.Tesi, L. Sorace, D. Pinkowicz, J. Jover, E. Ruiz, R. Sessoli, A. Cornia, Chem. Eur. J. 24 (2018) 8857.

[9] A. Altomare, M. C. Burla, M. Camalli, G. L. Cascarano, C. Giacovazzo, A. Guagliardi, A. G. G. Moliterni, G. Polidori, R. Spagna, J. Appl. Cryst. 32 (1999) 115. 
[10] G. M. Sheldrick, Acta Cryst. C71 (2015) 3.

[11] O. V. Dolomanov, L. J. Bourhis, R. J. Gildea, J. A. K. Howard, H. Puschmann, J. Appl. Cryst. 42 (2009) 339.

[12] T. Vermonden, D. Branowska, A. T. M. Marcelis, E. J. R. Sudhölter, Tetrahedron 59 (2003) 5039.

[13] (a) L. J. Kershaw Cook, R. Kulmaczewski, R. Mohammed, S. Dudley, S. A.

Barrett, M. A. Little, R. J. Deeth, M. A. Halcrow, Angew. Chem. Int. Ed. 55 (2016) 4327 ;

(b) N. Bridonneau, L. Rigamonti, G. Poneti, D. Pinkowicz, A. Forni, A. Cornia, Dalton Trans. 46 (2017) 4075;

(c) K. S. Kumar, I. Salitros, N. Suryadevara, E. Moreno-Pineda, M. Ruben, Eur. J. Inorg. Chem. 2018 (2018) 5091;

(d) I. Galadzhun , R. Kulmaczewski, M. A. Halcrow, Magnetochemistry 5 (2019) 9.

[14] (a) A. Hauser A. Coord. Chem. Rev. 111 (1991) 275;

(b) S. Marcen, L. Lecren, L. Capes, H. A. Goodwin, J. F. Létard, Chem. Phys. Lett. 358 (2002) 87;

(c) J. F. Létard, P. Guionneau, O. Nguyen, J. S. Costa, S. Marcen, G. Chastanet, M. Marchivie, L. Capes, Chem. Eur. J. 11 (2005) 4582;

(d) A. Hauser, C. Enachescu, M. Lawson Daku, A. Vargas, N. Amstutz, Coord. Chem. Rev. 250 (2006) 1642;

(e) G. Chastanet, C. Desplanches, C. Baldé, P. Rosa, M. Marchivie, P. Guionneau, Chem. Sq. 2 (2018) 2. 